\title{
O Manuscrito de Piranga (MG)
}

\author{
Paulo Castagna
}

\section{Quase um acaso}

Em fins de agosto de 1991, após a conclusão de minha tese de mestrado, o prof. Olivier Toni me confiou a tarefa de propor ao Instituto de Estudos Brasileiros da USP (IEB), a doação do acervo de microfilmes do Departamento de Música da Escola de Comunicações e Artes, resultado de visitas suas a alguns arquivos musicais de cidades mineiras na década de 1970.

Decidi, então, examinar o conteúdo dos rolos antes de contatar o prof. José Sebastiáo Witter, diretor do IEB, começando pelo de número 7 onde, segundo o prof. Toni, estavam microfilmados alguns papéis, da cidade de Piranga (MG), que pareciam ser "muito antigos". Utilizando as leitoras do Centro de Apoio à Pesquisa em História da USP, localizei o material que procurava entrc os fotogramas 37-158.

Naquele dia eu me deparei com o que algumas semanas depois eu iria confirmar: uma das mais antigas coleções de música já encontradas no Brasil.

\section{A descoberta}

Às seis horas da tarde, de 3 de maio. de 1975, chegava em Piranga, ${ }^{1}$ pela segunda vez, o grupo de pessoas reunido pelo prof. Toni,-2 numa tentativa de microfilmar o arquivo de d. Terezinha Aniceto, ${ }^{3}$ constituído de papéis de música mineira dos séculos XVIII e XIX, outrora conservados pelo seu pai. A notícia havia sido dada pelo padre Renato, do Seminário de Mariana, que rezava as missas dominicais, em Piranga, e que logo reconheceu a importância dos documentos da cidade.

O trabalho da equipe se estendeu até às 22 horas, extremamente dificultado pela fraca luminosidade do local e pela inexperiência na operação da microfilmadora, acarretando uma exposição insuficiente da maioria dos papéis encontrados.

O grupo então retornou a São Paulo, deixando naquela cidade os manuscritos, porém, grande parte microfilmados em dois rolos, juntamente com os exemplares de outros arquivos de Minas Gerais.

Durante dezesseis anos esses rolos permaneceram guardados no armário da sala do prof. Toni, no Departamento de Música da Escola de Comunicaçóes e Artes e, à exceção de algumas transcrições e execuções feitas nesse período, a documentação de Piranga não chegou a ser estudada do ponto de vista musi- 
cológico, sendo atualmente conhecida por apenas alguns pesquisadores.

Os catálogos de música colonial brasileira até hoje publicados não relacionam com precisão as cópias de música encontradas nessa localidade e vários musicólogos, como o prof. Régis Duprat, me comunicaram pessoalmente o desconhecimento de estudos sobre esse arquivo. De acordo com a literatura especializada e com informações recolhidas entre pesquisadores, o manuscrito de Piranga é um dos mais antigos conjuntos de cópias de música até hoje encontrados no país, e o maior documento musical brasileiro em notação branca já descrito.

Manifestei ao prof. Toni, na ocasião, o interesse em desenvolver uma pesquisa sobre o material localizado naquela cidade, o qual prontamente me autorizou a iniciar o trabalho. Esta comunicação é o primeiro passo para levar a público a descoberta e sua importância para a musicologia brasileira.

\section{O manuscrito}

Entre os papéis preservados em Piranga, o prof. Toni e seu grupo microfilmaram um conjunto de 56 folhas amarradas, mas sem numeração, com cerca de $25 \mathrm{~cm}$ de altura por 17 de largura (pelo que se pode avaliar nos fotogramas). Uma peça incompleta no início do documento indica a falta de pelo menos uma folha, onde poderiam estar informaçōes sobre o autor e a data da composição ou cópia das partes. É possível que essa folha tenha se perdido durante a própria confecção do manuscrito, uma vez que a peça que abre o conjunto ("In monte oliuete") volta a aparecer, completa, nas folhas $12 \mathrm{v}-13 \mathrm{r}$, considerandose como primeira a folha faltante.

O copista utilizou papel branco, desenhando entre dois e dez pentagramas por página, frente e verso, provavelmente com o auxílio de uma pena de cinco pontas. As partes de "Tiple" e "Tenor" na página à esquerda (de cima para baixo) e "Altus" e "Bassus" na página à direita indicam tratar-se o documento de um antigo livro de estante, para ser utilizado pelos quatro cantores do coro, não existindo partes de acompanhamento. Essa disposição já era bastante comum nas cópias européias do século XVI servindo, inclusive, para a edição. Todas as peças são religiosas com o texto em latim, a maioria delas destinada à Semana Santa.

A notaçăo musical é do tipo branca e redonda, a qual vinha caindo em desuso no velho continente já no século XVII, dando lugar ao sistema atual. Não existem barras de compasso. Barras simples e duplas são utilizadas apenas com funções fraseológicas. A maioria das peças utiliza as claves de dó na 1a. linha ("Tiple"), dó na 3a. ("Altus"), dó na 4a. ("Tenor") e fá na 4a. ("Bassus"), com a indicaçáo "C" e o si b na armadura. Existem, no entanto, algumas exceções, onde aparecem as claves de sol na 2a. linha ("Tiple"), dó na 2a. ("Altus"), dó na 3a. ("Tenor") e dó na 4a. ("Bassus"): "Pueri hebreorum" (ff.3v4r), "Aleluya" (ff. 52v-53r), "Laudate Dominù" (ff. 53v.55r) e "Gloria Patri" (ff. 55v.-56r), as três últimas com a indicaçáo "C3" e sem o bemol na armadura. O "Sanctus" (ff. 2v-3r) e o "Vespere autem Sabati" (ff. 56v-57r) utilizam o 
primeiro conjunto de claves mencionado, mas enquanto na primeira existe o sinal "C", sem o bemol na armadura, na segunda observamos o sinal "C3" e o uso do bemol.

Não existe a data da cópia no documento. Indicações posteriores, com letras completamente diferentes daquela empregada nos texios latinos e incomuns no século XVIII, não parecem ter relação com a produção do manuscrito e, provavelmente, foram os fatores que levaram o pe. Renato a catalogar essas peças como cópias do século XIX": "Piranga 21 de maio de 1870" (f. 9v.); "Piranga 13 d 10bro. de 1871" (f.11v.); "a data que tem ha atras foi de 77" (f. 11v.). Não foi possível, ainda, realizar uma análise detalhada das características paleográficas dos textos religiosos. Os primeiros exames, contudo, apontam na direção de uma letra típica da primeira metade do século XVIII. A datação, ainda aproximada, é corroborada por características da grafia musical: a notação branca, ${ }^{6}$ as claves e armaduras, os sinais de mensura (C e C 3 ), a escrita "a cappella" e a disposição das partes vocais nas folhas do documento. Mas o fator que atesta a antiguidade das composições é a sua análise musical, a qual adiante será abordada.

O conteúdo do manuscrito, segundo os títulos encontrados com a mesma letra dos textos latinos, é o seguinte:

1 - (ff. (lr)-3r): (falta a primeira folha, que levaria o título. Há duas peças nesta seção): "In monte oliuete" (f. 2r, apenas "Altus" e "Bassus"); "Sanctus" (ff. 2v-3r).

2 - (ff. 3v-5r): "(Antífonas) P.a odestribuir dos Ramos".

3 - (ff. 5v-11r): "Bradados. de Domingo de Ramos".

4 - (ff. 1lv-21r): "Antífona do 1. o N. Imferia 4a."

5 - (ff. 21v-25r): "Antífona. dos Benedictus".

6 - (ff. 25v-26r): "Antífona. domiserere".

7 - (ff. 26v-36r): "Antífona. Imferia 5a".

8 - (ff. 36v-41r): "Antífona. debenedictus".

9 - (ff. 41v-43r): "Antífona. domiserere".

10 - (ff. 43v-46r): "Tratus. p.a a Sesta Fr.a".

11 - (ff.46v-49r): "Bradados. de Sesta Fra.a".

12 - (ff. 49v-50r, título com outra letra): "Adorasaõ da Cruz".

13 - (ff.50v.56r): "Tratus. p.a o Sabb.do Sancto".

14 - (ff. 56v-57r): "Antiphona".

\section{Um exemplo}

Nas folhas 3v-4r encontramos o "Pueri hebreorum", a primeira antífona ad processionem do Domingo de Ramos. O facsímile dessas duas páginas foram extraídos das fotogramas 40 e 41 do rolo n. 7.

Restaurei a música, a ortografia e a prosódia do texto latino, transpondo a peça uma terça menor abaixo do tom original, para facilitar sua execução por um agrupamento coral. Os erros do copista, como se observa, não são freqüentes, bastando a versão para a notação moderna e o ajuste do texto. Contudo, 
existem incertezas quanto às alterações cromáticas (acidentes ocorrentes) encontradas no manuscrito, pois certas passagens ainda deixam dúvidas, ao se utilizarem os acidentes indicados.

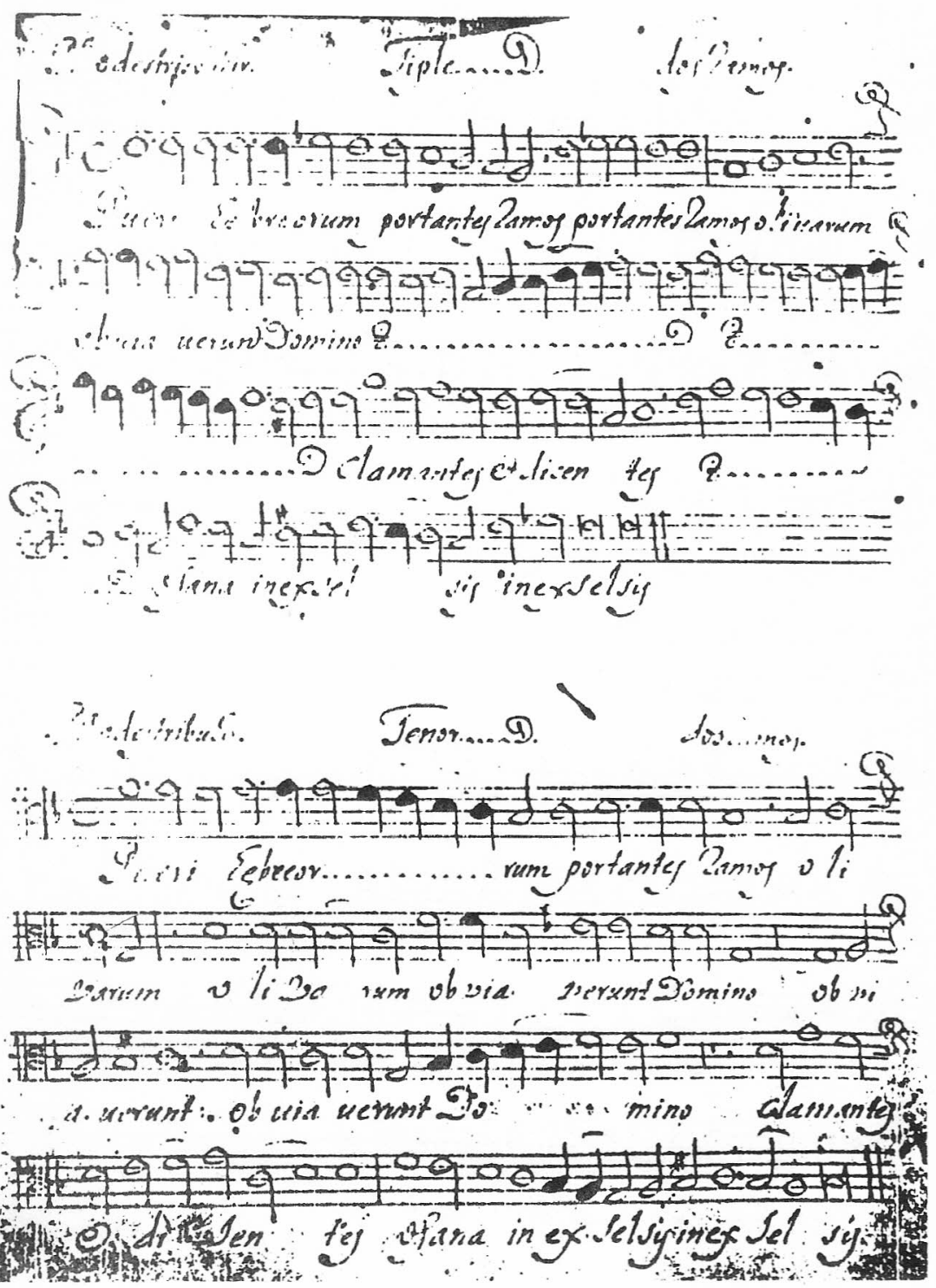




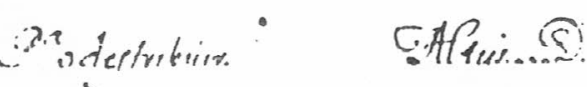

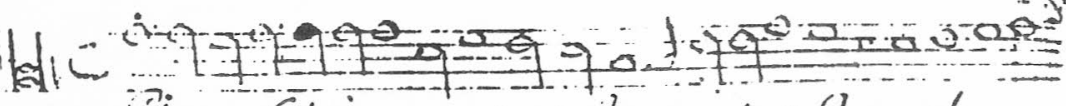

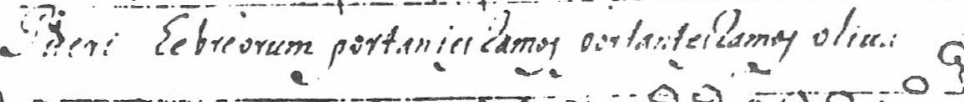

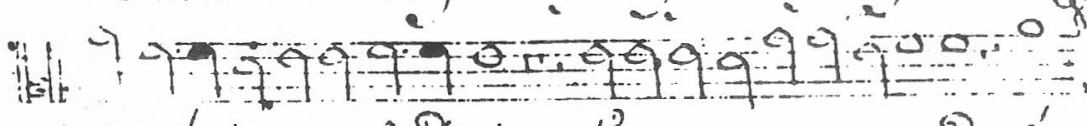

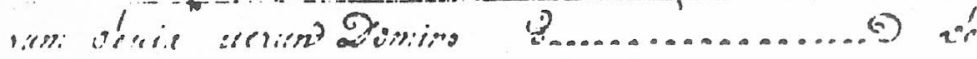
1.

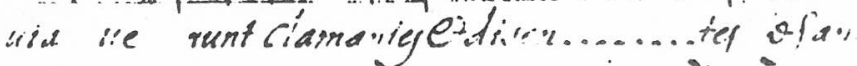

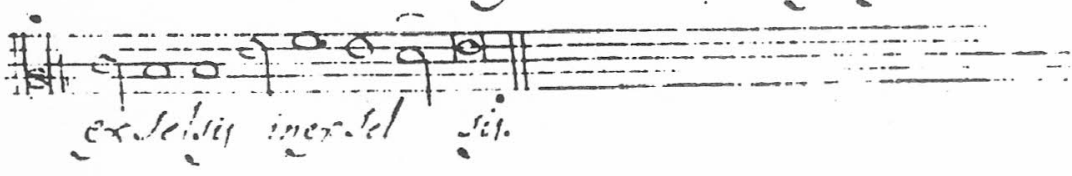

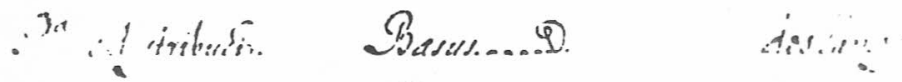

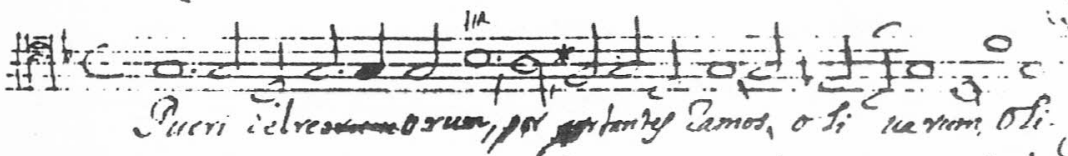
7 1.

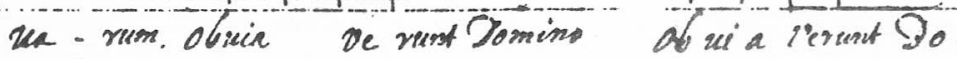

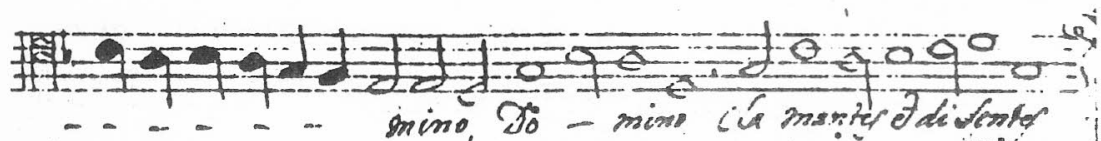

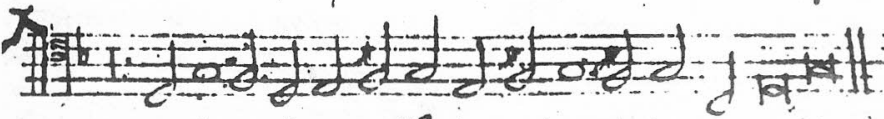

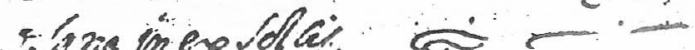
isiti. 
PUER I HEBRAEORUM

(antífons para o Domingo de Ramos)

REstaURAÇÃo: PAULO CASTAGNA

Manuscrito de Piranga (MG) [1 a metade do séc. XVIII]
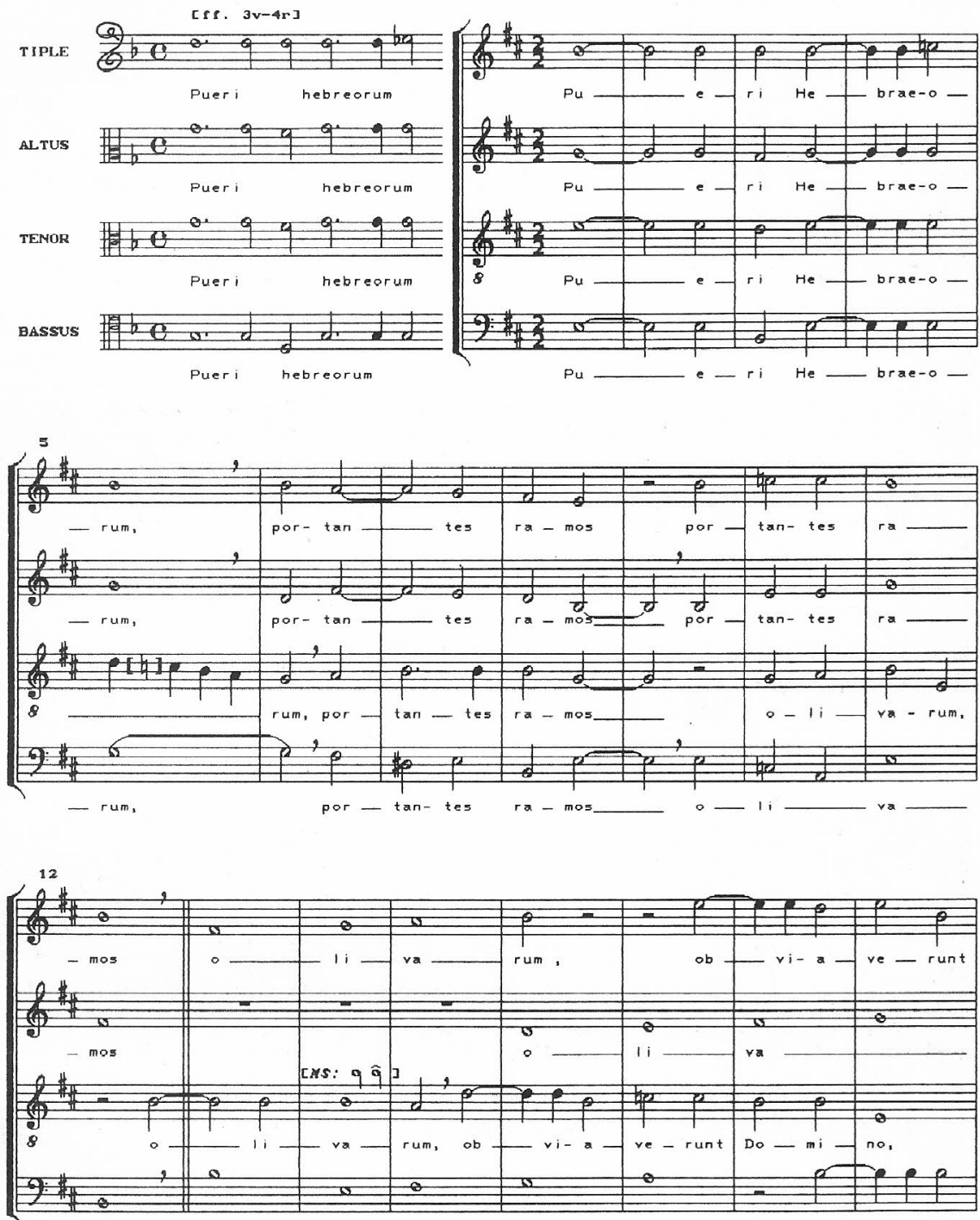

- rum,

rum,

$o b-v i-a-$ 

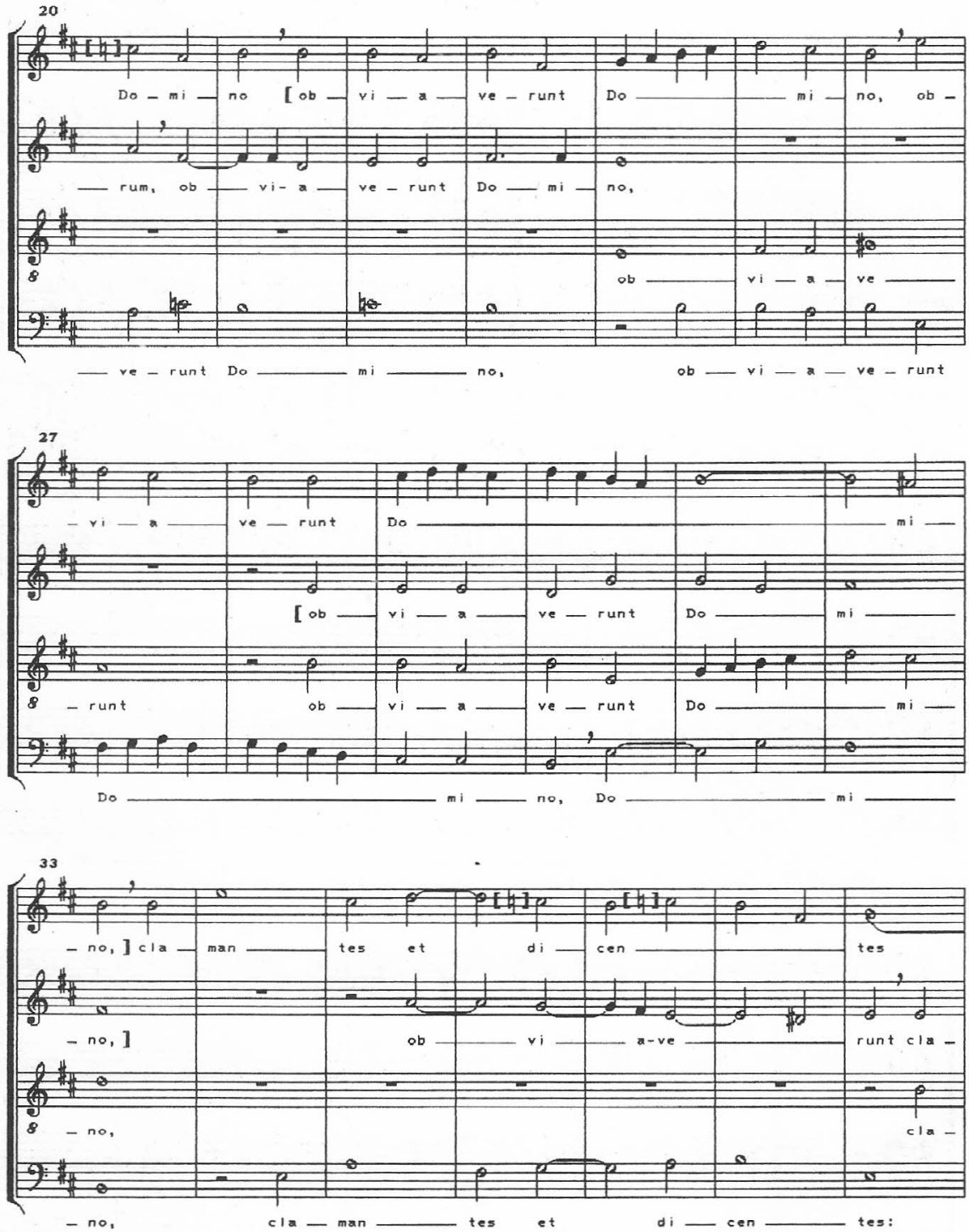

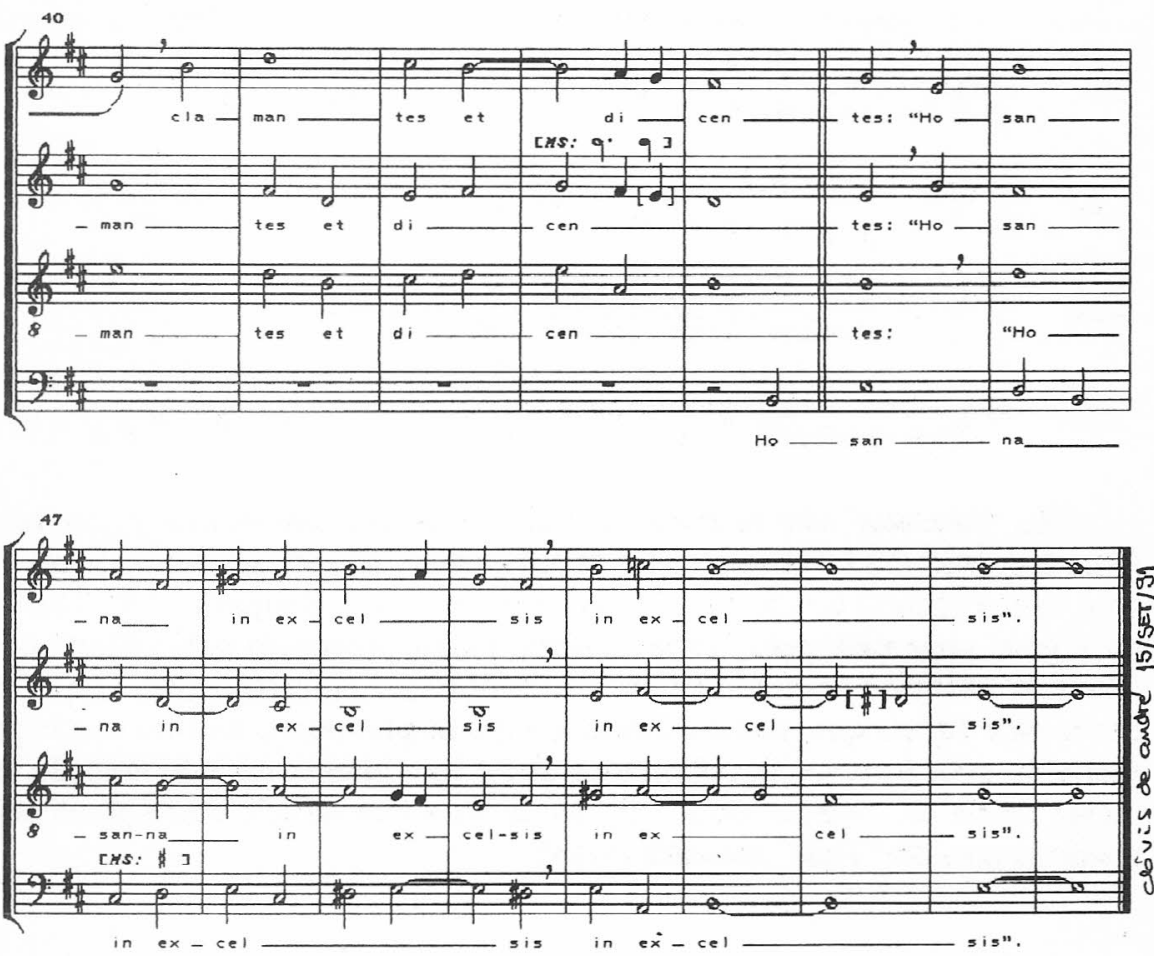

Há, nesta peça, pelo menos três características de um estilo musical anterior ao da produção brasileira conhecida da segunda metade do século XVIII, mais especificamente, típicas da música européia do século XVI:

1) a utilizaçáo do sistema modal;

2) o uso de imitações, envolvendo motivos diferentes;

3) os repousos (pontuações) por "cláusulas" e "cadências". É interessante ressaltar que esses elementos ainda eram comuns na música religiosa portuguesa e mesmo sul-americana de fins do século XVII, tornando-se arcaicos apenas no século seguinte.

A peça está no 10. modo (dórico), em "cantus mollis" (escala de sol com o si b na armadura) e não no modo menor, haja visto o uso esporádico do VI

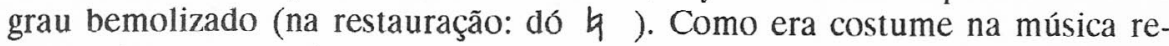
nascentista, a peça alterna os modos autênticos e plagais entre as vozes utilizadas, o "Tiple" determinando o modo do conjunto. As alterações cromáticas no III e VI graus (sol \# e dó $甘$.) têm as funções de evitar a ocorrência do trítono melódico e polarizar o IV e V graus da escala, os mais importantes, nesse modo, após o I grau ("finalis"). O mesmo ocorre com a alteração do IV grau (lá \# ) com a finalidade de provocar a cláusula no V (si): 


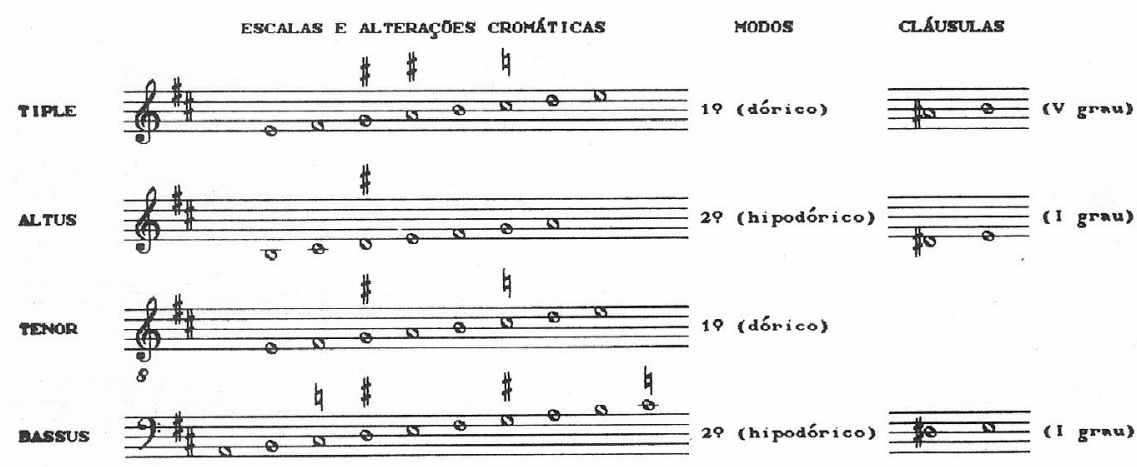

As "cláusulas" são terminações polifônicas que envolvem a preparação $(P)$, suspensão (S) e resolução (R) de uma das vozes, um semitom abaixo do grau onde ocorrerá o repouso (C), como acontece nos compassos 33 (cláusula no V grau, provocada pelo "Tiple"), 39 (no I grau, provocada pelo "Altus" e 54 (cláusula final no I grau, provocada pelo "Altus"). A alteração da nota que ascende para aquela que recebe a cláusula, a fim de provocar o movimento de um semitom, mais fortemente polarizador que o tom inteiro, era denominada, na antiga teoria da "musica ficta", de "subsemitonium modi", correspondendo, abaixo, à nota do "Tiple" marcada com R:

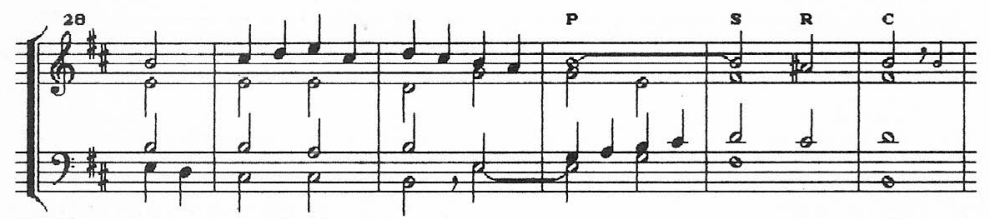

Já as "cadências" são terminações homofônicas, com o encadeamento de pelo menos dois acordes, ocorrendo, aqui, nos compassos 12 (V grau) e 45 (I grau). Neste fragmento, nota-se uma cadência do tipo I-V:

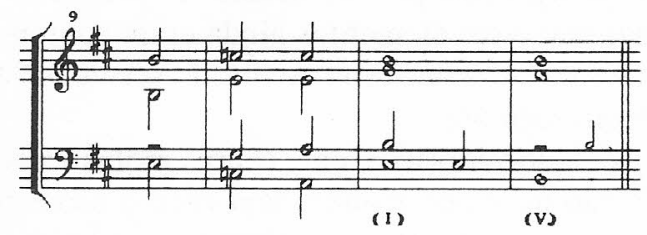

No século XVI, as cláusulas e cadências do 10. modo ocorriam principalmente no I, IV e $\mathrm{V}$ graus. Eram facultativas no III e excepcionais no VII grau. No "Pueri hebreorum" há repousos apenas no I e V graus, revelando simplicidade no tratamento das pontuações e, conseqüentemente, um pequeno número de alterações cromáticas. 
Na parte do "Tenor" existem barras simples, dividindo a peça em três seções que, no caso, podemos chamar de $\mathrm{A}, \mathrm{B}$ e C.

No "Tiple" estấo separadas pela barra simples apenas as seçôes A e B, não existindo o sinal nas demais vozes. Utilizei, na restauração, a barra dupla para indicar essas divisões.

O que podemos observar, agora, é a existência de uma seção A homofônica, finalizada pela cadência no $\mathrm{V}$ grau, seguida da seção $\mathrm{B}$, polifônica, onde quatro motivos se entrelaçam por imitação, havendo sempre o "stretto" entre duas das quatro vozes. Os motivos recebem modificações no desenho e na altura, à medida que são reapresentados. Na seção $\mathrm{C}$ volta a aparecer o motivo 4 , também imitado em "stretto", mas dentro de uma textura intermediária entre a polifônica e a homofônica, dando lugar à cláusula final no I grau. Para simplificar a compreensão da estrutura da peça, segue-se a reorganização de todo o material musical do "Pueri hebreorum", de acordo com a análise apresentada:

\section{Seção A}

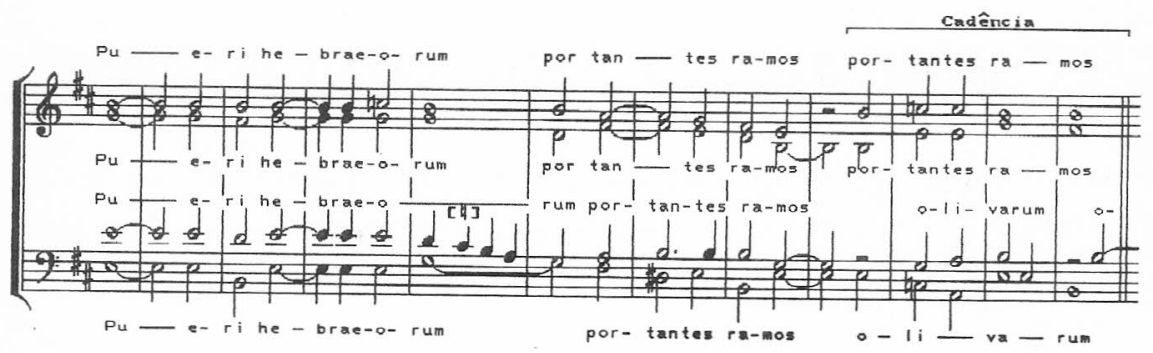

Seção B

Motivo 1
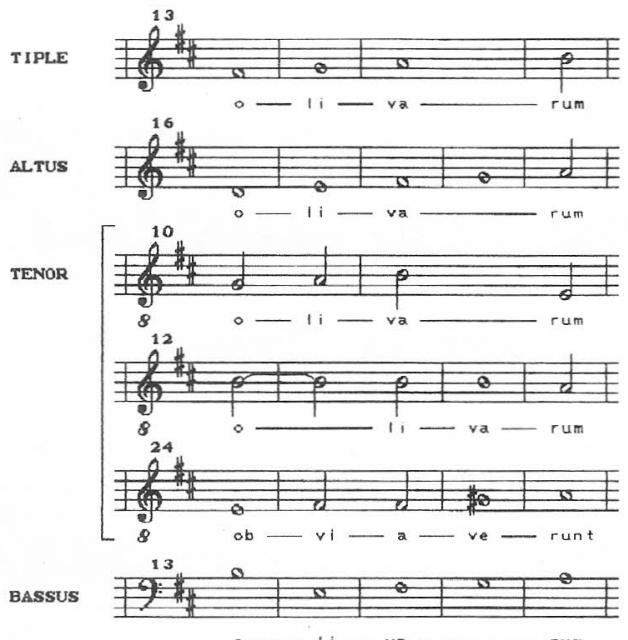

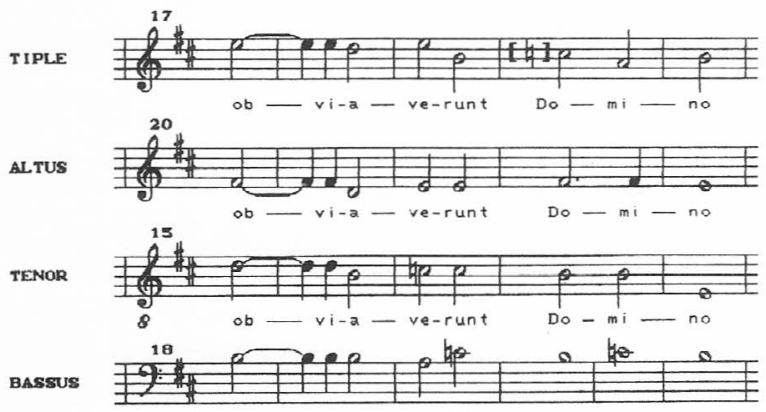

ob - vi-a - ve-runt Do-mi-no

Motivo 3
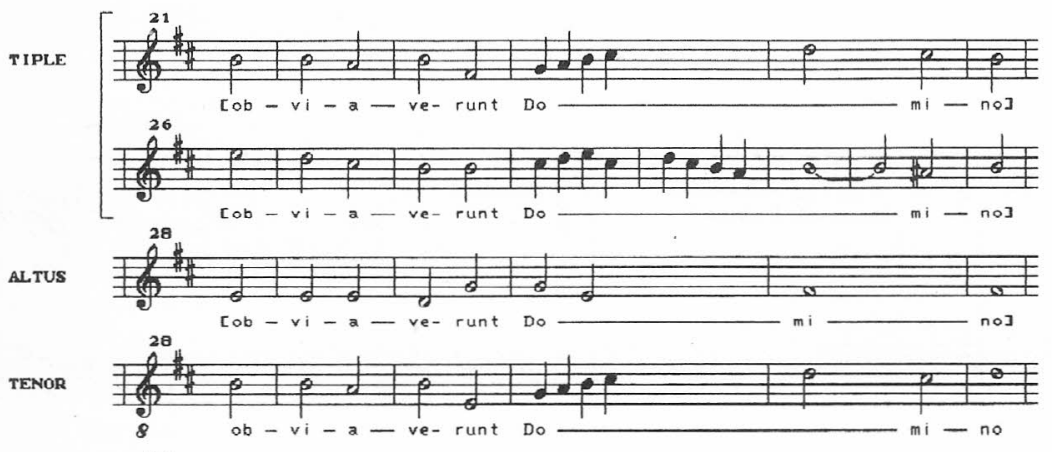

Bassus

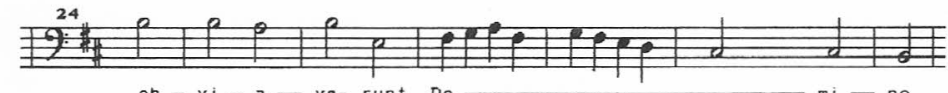

ob - vi-a-ve- runt Do

MoTIvo 4
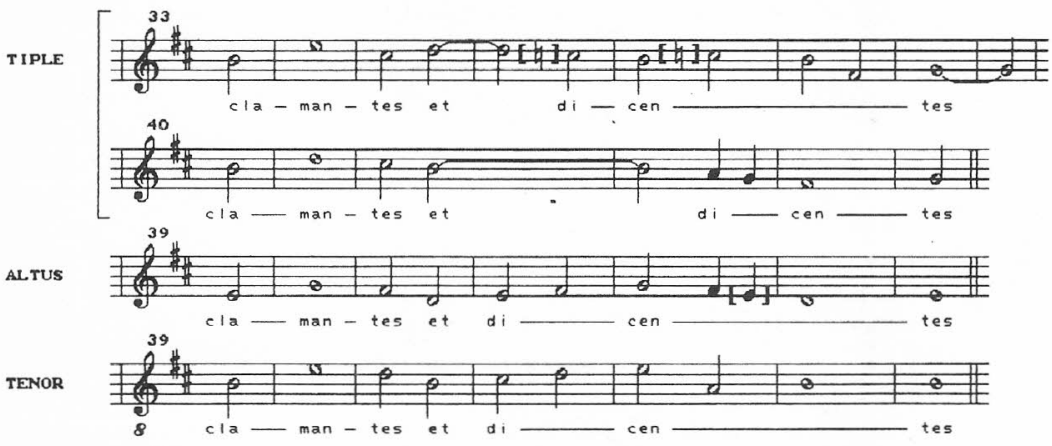

BASSUS

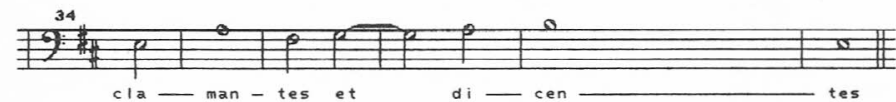


Seção C
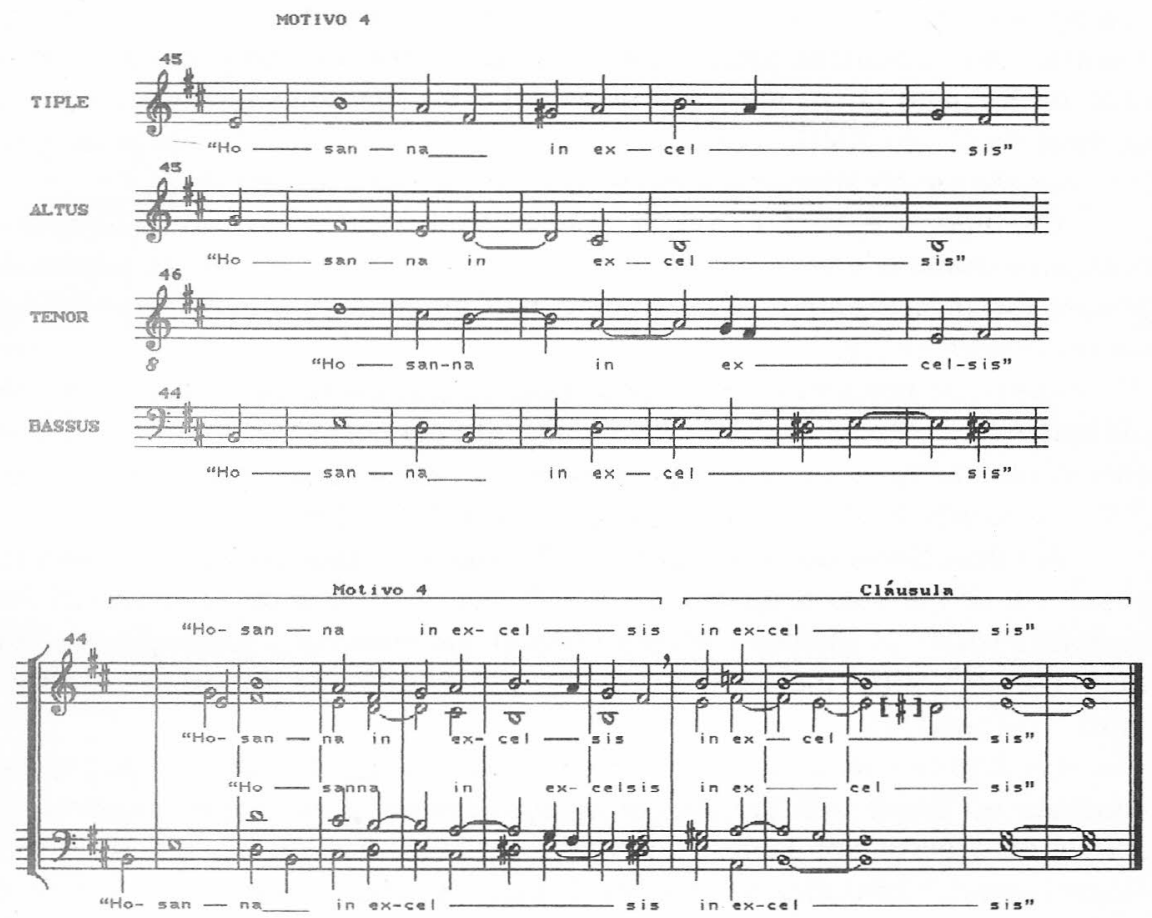

Curiosas, nessa antífona, são as quintas paralelas entre o "Altus" e o "Bassus" nos compassos 16, 17 e 18, além das quartas paralelas entre "Tiple" c "Altus" nos compassos 35 e 36. Esse dado provavelmente será útil para a datação e determinaçấc da origem da música contida no documento. O mesmo se aplica no manuscrito de Piranga, à coexistência de obras polifônicas e homofônicas, modais e tonais, indicando uma época de transição de linguagens, quando da escrita dessas peças.

Possiveis origens

A ausência de informações sobre a autoria e data das obras, no manuscrito, gera uma série de questões que não poderão ser solucionadas sem uma pesquisa cuidadosa. Neste momento, ainda não é possível saber, por exemplo, se as peças foram compostas no Brasil ou na Europa.

A prática musical brasileira nos séculos XVI e XVII foi bem maior do que a imaginada por muitos musicólogos, apesar de nenhum documento musical escrito no Brasil daquela época ter sido ainda recuperado. Mas já em 1650 foram encontrados, dentre os bens do falecido Pascoal Delgado, em Santana do 
Parnaíba (SP), "três livros de canto de órgão e mais cartapácios e papéis". ${ }^{7}$ Indicadores da existência de uma atividade composicional no Brasil já no século XVII são os pagamentos por música executada em cerimônias fúnebres, que começaram a se tornar freqüentes em São Paulo, por volta dessa data. ${ }^{8}$ Mesmo a música para a Semana Santa (como é o caso da maioria das peças do manuscrito de Piranga) já era praticada no Brasil nos primórdios da colonização ${ }^{9}$ e, do final do século XVII, conhecemos hoje registros da execução da peças para essa ocasião até no interior dos navios que vinham de Portugal. ${ }^{10}$

Contudo, a música européia, sobretudo ibérica, penetrou no território brasileiro durante todo o período colonial. ${ }^{11}$ No século XVIII, os papéis de música estrangeiros ainda eram comuns na Capitania de Minas Gerais ${ }^{12}$ e em outras cidades brasileiras. ${ }^{13}$

Pesquisas recentes estão demonstrando a existência, em Minas Gerais, de manuscritos com música portuguesa composta em períodos anteriores, dentre eles várias coleções de canto gregoriano, o "Cum descendentibus" (século XVI), de Ginés de Morata ${ }^{14}$ e o "Passio Domini Jesu Christi". ${ }^{15}$

A importância do manuscrito de Piranga não está no fato de o mesmo conter ou não música composta no Brasil, mas de apresentar um material que permitirá conhecer melhor a prática musical que antecede a produção brasileira do século XVIII e mesmo o esclarecimento de questóes importantes sobre a música colonial mineira.

De acordo com a literatura especializada o único conjunto de papéis encontrado no Brasil com música em notação branca, e até agora estudado, foi aquele descoberto por Jaelson Trindade, em Mogi das Cruzes, e descrito por Régis Duprat. ${ }^{16}$ São cerca de quarenta folhas copiadas na década de 1730 , onde aparecem os nomes dos irmãos Faustino e Angelo do Prado Xavier, contendo, entre outras, peças cujos textos aparecem também no manuscrito de Piranga. Segundo Duprat, ${ }^{17}$ há cópias muito posteriores a essa época, dos "Bradados a 4 para Domingo / Ramos, e sexta fr.a da / Payxaõ / De Faustino do Prado Xavier" e dos "Tractos para as profecias de Sexta fr.a da Payxan / a 4 / De Fausto do Prado Xer". Uma delas aparece no catálogo O Ciclo do Ouro, ${ }^{18}$ em cópia de 1928. Note-se a semelhança do início dos "Tractos" de Mogi, com o fragmento correspondente dos "Tratus p. a a Sesta Fr.a" do manuscrito de Piranga (ff. $43 v-44 r)$ : 


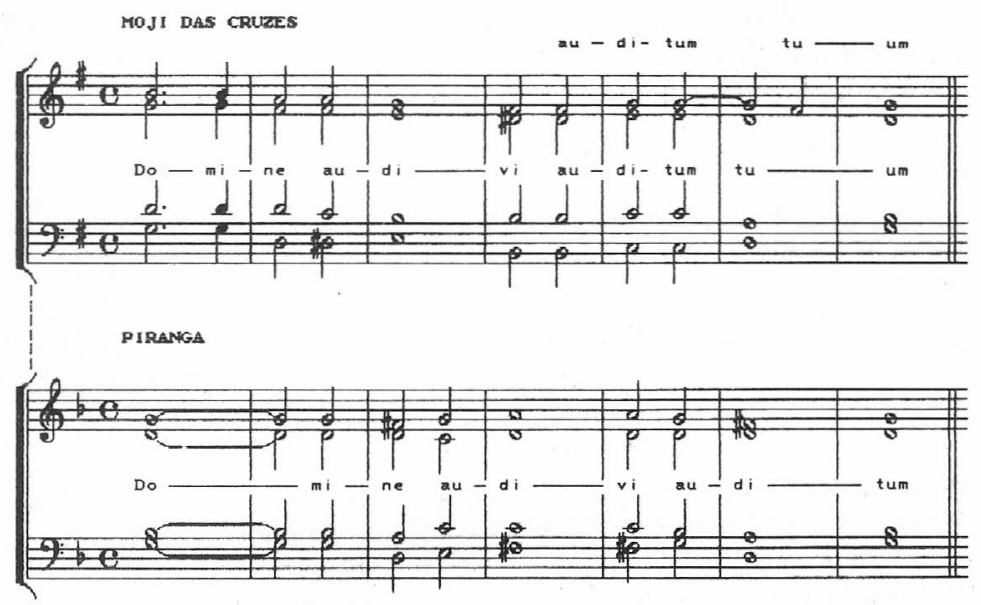

Régis Duprat imprimiu, no Garimpo Musical, ${ }^{19}$ um facsímile de três páginas do conjunto de Mogi, contenuio partes do "Bassus" dos "Bradados a 4". Superpondo um dos fragmentos com o trecho do "Bassus" que utiliza a mesma letra nos "Bradados de Sesta Fr. a" de Piranga (f. 49r), percebe-se a interessante correspondência:

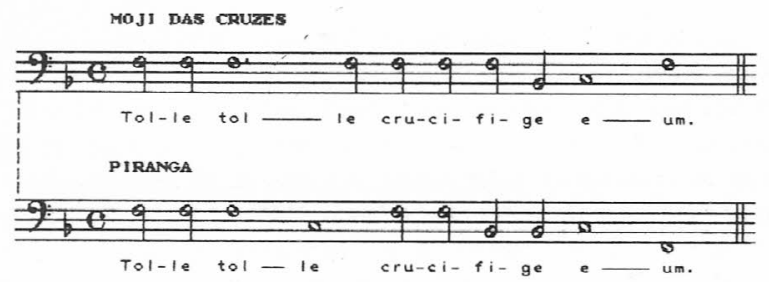

Existe, portanto, alguma relação entre os conjuntos de Mogi e de Piranga, que será melhor conhecida assim que se publicarem os papéis estudados por Duprat. Teria o autor de um deles se baseado no outro, ou ambos adaptaram música de uma outra fonte ainda desconhecida? Fenômenos parecidos também ocorrem na música colonial mineira. O Ciclo do Ouro arrola peças semelhantes que não trazem indicação de autor, muitas delas atribuídas, no catálogo, a Manoel Dias de Oliveira.

É muito provável que novas pesquisas acusem a presença, no Brasil, de música anterior à segunda metade do século XVIII, ora atribuída a compositores mineiros dessa época, propiciando a abertura de investigações não empíricas sobre as origens da atividade composicional na colônia.

Infelizmente, a parca quantidade de recursos destinada à musicologia $\mathrm{e} a$ falta de trabalhos que envolvam a restauração, edição, estudo e gravação da an tiga produção musical brasileira, dificultam consideravelmente o desenvolvimento de pesquisas que resultem na efetiva veiculação desse repertório. 
Espero estar contribuindo nesse sentido, ao iniciar a transcrição e estudo do manuscrito de Piranga, cujos resultados certamente terão grande importância para o conhecimento da prática musical brasileira do século XVIII.

Paulo Augusto Castagna é pesquisador, graduado e pós-graduado pelo Departamento de Música da Escola de Comunicações e Artes da USP e ex-bolsista do CNPq, da FUNARTE, e da FAPESP. Integra a Comissão de Publicação da revista Música.

\section{Notas}

1. Piranga, anteriormente Guarapiranga, foi uma freguesia mineira cujas origens se encontram já em 1694, quando lá foi edificada uma capela com a invocação de N.Sa. da Conceição. Situa-se hoje na estrada de terra que liga Conselheiro Lafaiete e Viçosa, distante cerca de $60 \mathrm{~km}$ da primeira. Sua população é aproximadamente de 3 mil pessoas na área urbana e pouco mais de 16 mil na zona rural.

2. Faziam parte do grupo, entre outros, Aluízio Viegas, Alexandre Faragó Jr., Cláudia Benatti. Marcos Branda Lacerda e Cláudia Toni.

3. Da. Terezinha Aniceto residia na primeira casa da Rua Santa Efigênica. Maria Conceição Rezende, em A música na história de Minas Colonial (Belo Horizonte: Itatiaia: Brasília: INL. 1989. p.719) cita desta maneira o arquivo de Piranga, entre outros onze acervos de Minas Gerais: "Piranga -- Acervo particular -- pertencente à família de Terezinha Aniceto. Total de peças: 116)".

4. Maria Conceição Rezende (op. cit., p. 748-749) publicou o seguinte texto de Edino Krieger. sobre o arquivo de Piranga: "Foi feito apenas o levantamento do material, pelo Revmo. pe. Renato, do Seminário de Mariana, e consta de: Missa de Suassuy, composta em 1552: Missa, por João do Couto; Credo, de Maciote; Missa Moura, reproduzida pelo Pingente: Missa Serzult, proveniente de Alto do Rio Doce; Missa, de Justiniano Ribas; Credo, por Jeronymo de Souza: Missa segunda, de Lial; Missa, de Francisco de Sales; Credo, de Leôncio: Missa quarta, do maestro Francisco Chagas; Missa da Piedade; Missa das Dores; Missa de Requiem; Missa a três rozes; proveniente de São Domingos; Missa do pe. João de Deus Castro Lobo; Missa da roça, reprodução e cópia do Pingente (Alto do Rio Doce), de J. G. F. Dunga; Credo, de Salles Couto: Missa, do pe. Joaquim de Paula; Oficio para Sexta-feira Santa, cópia do século XIX: Responsório I e Invitatório para Matinas da Ressurreição, cópias do século XIX; Canto das 3 Marias, proveniente de Barra do Bacalhau -- cópia do século XIX; Dominica in Palmis; Ofício de Ramos, proveniente de Ubá; Antifonas para 4a., 5a. e 6a. Feira Santa; Bradados ou Canto da Paixão; Antífonas para lava-pés. Outra Antífona -- cópias do século XIX; Ofício de Trevas, cópias do século XXIX; Tracto para Sábado Santo; Motetos para procissão de Passos, cópias do século XIX: Responsório para Nossa Senhora das Dores; Stabat Mater, cópias do século XIX: Popule meus, cópias do século XIX; Tracto, para instrumentos, de Jeronymo de Souza Sobrinho: Antífonas, cópias de 1821; Antifonas de Benedictus; Plorans, cópias do século XIX. Tremit mundo; Te Detum dos seguintes autores: L. A. Silva Guimarães, pe. João de Deus do Couto, e outros sem indicação de autores: José Joaquim, João do Couto, A. de Menezes. Augusto Gomes. F.Sales. Francisco Atanásio, Marcos Coelho Neto, Jeronymo de Souza, Leôncio Francisco das Chagas. Joaquim de Paula, Francisco Manoel etc. (...)

"Novenas", com os seguintes títulos: da Senhora da Conceição, Novena a Nossa Senhora, com partes de oficlides (copia do século XIX), Novena do Espirito Santo.

Muitos motetos avulsos, sendo muitas cópias do século XIX. O total de peças do acervo é de 116."

5. Várias das peças indicadas no texto de Edino Krieger, na nota anterior, coincidem com títulos encontrados no manuscrito do qual trata este artigo, como "Antifonas para 7a., 5a. c 6a. Feira 
Santa: Bradados ou Canto da Paixảo", "Tracto para Sábado Santo", "Antífonas de Benedictus" e outras. É possivel que o pe. Renato tenha se referido a este manuscrito, porém. indica os papéis como "cópias do século XIX".

6. Régis Duprat, em "A polifonia portuguesa em obras de brasileiros" (Pau Brasil, n. 15. 1986. p.70-71) informa: "Com exceção dos manuscritos de Mogi das Cruzes, a música conhecida do período colonial brasileiro é escrita na atual notação vigente. A exceção comprova a vigência. pelo menos em São Paulo, no final da década de 1720. da notação antiga. Defrontamo-no, ao que parece, com datas-limite. Na América espanhola os arcaísmos notacionais adentram todo o primeiro quartel do século XVIII".

7. Esta informação é encontrada na coleção Inventários e Testamentos, v. 40, 1955, p. 144: "Foi avaliado três livros de quãto dorguo e mais quarta pasSios e papeis em quatro mil rs............4.000".

8. Cf. Os Inventários e Testamentos, 1920-1977, em 44 volumes. Em minha dissertação de mestrado, Fontes bibliográficas para a pesquisa da prática musical no Brasil nos séculos XVI e XVII (São Paulo: ECA-USP, 1991. 3 v.), recolhi documentação suficiente para comprovar a extensão da prática musical naquele período.

9. Em uma carta de Antonio Blasques aos Padres e Irmãos de Portugal, datada de 9 de maio de 1565, são mencionados os ofícios da Semana Santa de 1565 na Bahia: "Concertado y ornado nuestro monumento deste modo, se hizieron los officios de la Semana Sancta em nuestra Iglesia con mucha devoción, de modo que, aunque en la See se solemnizassen con canto, dexavan todo y se venían a nuestra Casa". Cf. Serafim Leite, Monumenta brasiliae $N$ (Roma: Monumenta Historica S.I., 1960, doc. 16, parágrafo 9, p. 194).

10. É o que se lê na Relação da Viagem, de Frutuoso Correa, escrita em São Luiz a 26 de maio de 1696: "No Domingo de Ramos, na 4a. feira de trevas, na 5a. feira e 6a. da Paixão se fizeram os ofícios da Semana Santa, cantando à harpa la lição em cada Noturno“. Cf. Serafim Leite. História da companhia de Jesus no Brasil (Lisboa: Portugalia; Rio de Janeiro: Civilização Brasileira e INL, v. 9, 1949, apêndice C. parágrafo 8, p. 388).

11. Regis Duprat (A polifonia portuguesa em obras de brasileiros, op. cit., p.70) traz esta notícia: "O certo é que a música portuguesa dos séculos XVI a XVIII, nulamente estudada ou cultivada no Brasil de hoje, deveria integrar espontaneamente os repertórios das capelas de música do Brasil colonial".

12. Veja-se, por exemplo, este texto, publicado por Maria Conceição Rezende (op. cit., pp. 554-555): "Dr. Geraldo Dutra de Morais, em 'Origens da Música Barroca' (Estado de Minas 5/6/1974), informa: 'Foi encontrada no mosteiro de São Bernardo, Lisboa, em carta de frei Vicente Pais da Anunciação, mestre de capela, em 11 de fevereiro de 1750, no livro 'Copiador. no. 308 , maço 45', uma anotação cujo texto é: 'num dos caixotes de procedência de Lisboa. havia músicas para orquestra e coro, como missas, ofícios, música sacra etc.

Correspondência inédita coligida nos mosteiros dos Carmelitas Descalços, São Bernardo e Santo Agostinho, em Portugal, esclarece que os bispos marianenses costumavam encomendar repertórios de músicas eruditas, sacras e profanas, cujas partituras eram oferecidas aos regentes de orquestra das igrejas de Minas, preferencialmente Mariana e Ouro Preto.

"Uma das cartas, datada de 1741, dirigida a d. frei João da Cruz, bispo da Diocese do Rio de Janeiro, pelo organista frei Caetano de Santa Rosa, menciona a remessa das seguintes partituras: 'Missa Brevis', de Giovanni Pierluigi Palestrina; 'Benedicam Dominun', de Roland de Lassus; 'Sonata para Cravo', de Alessandro Scarlatti; 'Quinteto para Violas e Cravo', de Jean-Baptiste Lully, além de outras composições de Rameau, Frescobaldi e Monteverdi, cujos títulos não constam da fatura. Quando de sua peregrinação a Vila Rica, em 1745, d. frei Manuel da Cruz entregou ao pe. José de Andrade Moraes, cópias de várias partituras, recomendando-lhe que as distribuisse aos regentes das orquestras do Pilar e Antonio Dias. Outra dessas cartas, de 6 de abril de 1788, do dominicano frei Antonio de Castro Moreira, regente da Igreja da Graça, endereçada a d. Frei Domingos da Encarnação Pontevel, relaciona o envio de obras musicais dos seguintes compositores: William Bird, George Friedrich Handel, Francisco José Haydn, Wolfgang Amadeus Mozart e Henry Purcell. Desnecessário seria dizer da importância desse manancial de erudição, no aperfeiçoamento cultural dos músicos mineiros, familiarizados com 
a técnica de composição orquestral dos gênios europeus. ('Estado de Minas', 5/6/1974).

"Sobre a música profana importada, F. Curt Lange dá a seguinte notícia: 'Em 1794. Francisco da Cruz Maciel, sem dúvida mulato, copiou um Quarteto de Haydn, o qual deve ter sido tocado com muita freqüência, a julgar pelo uso de suas partes'.

"Trios e Quintetos de Boccherini, Quartetos de Pleyel, Duos para violino e baixo, já anônimos. por haverem sido copiados várias vezes, figuram como material que hoje classificaríamos para concertos de câmara"”.

13. José de Morais, na História da Companhia de Jesus, na Província do Maranhão e Pará (1759, livro III, cap. I, parágrafo 17), fala da entrada de papéis de música portugueses na catedral de Belém, durante a primeira metade do século XVIII: "A innata propensão do genio deste excelentissimo prelado (d. Frei Miguel de Bulhões) de tal sorte adiantou a bela harmonia da sua música, que não tem inveja a mais miúda e delicada solfa da côrte, donde se extrairão para esta catedral os melhores e mais harmoniosos papéis e cantorias". Cf. Candido Mendes de Almeida. Memórias para a história do extinto Estado do Maranhão. Rio de Janeiro: Typ. do Commercio de Brito \& e Braga, 1860. v. I, p. 190-191.

14. A partitura foi publicada e estudada por Regis Duprat em A polifonia portugucsa em obras de brasileiros, op. cit., p. 69-78.

15. Maria Conceição Rezende (op. cit., p. 723-724) indica a existência desse documento no Museu da Música da Arquidiocese de Mariana, deixando esta descrição: "Na área da música sacra há uma importantíssima coleção de 4 livros tendo, como página-título, as informações: "Passio Domini nostri Jesu Christi, in numeris digesta, alternisque Vocibus Quator Decantanda. seu potius deflenda: OPUS Francisci Ludovici. Musices Praepositi in Cathedrali Sede Ulyssiponensi".

A música se refere ao texto da Paixão, sendo quẹ cada livro tem melodias diferentes de acordo com as 4 vozes: "altus primus, altus secundus, tenor e bassus". Estas melodias se desenvolvem à maneira dos primórdios da polifonia: quando aparece o "cantus firmus", as vozes o fazem em gregoriano, uníssono. A escrita musical é do século XVII, bem como a notação. Os quatro livros são manuscritos e não trazem data: note-se que só após o Concílio de Trento, na Renascença, tornou-se uso colocar a data em algarismos romanos no frontispício dos livros. É um incunábulo. Todos os quatro livros têm a primeira e a segunda página iguais: aparece em letras muito antigas, na segunda página, uma belíssima dedicatória com belas iluminuras. à qual se refere dada à originalidade do texto onde o autor faz um jogo de palavras entre os instrumentos da Paixão de Cristo com a notação musical da época".

A autora também cita, na p. 565, "uma obra (Missa) encontrada em Piranga. (MG) - datada de 1553 ", que é melhor descrita na p. 748 (cf. a nota 4. deste artigo): "Missa de Suassuy. composta em 1552". Não existem estudos sobre essa peça. Relatos de pesquisadores que manusearam cópias dessa obra, acusam-na como freqüente nos arquivos mineiros e com data provavelmente incorreta. A música parece ter sido composta no século XIX.

16. As primeiras publicações, no Brasil, que tratam dessa descoberta, são as seguintes: Jaelson Trindade, Música colonial paulista: o grupo de Mogi das Cruzes. Revista do Patrimônio Histórico e Artístico Nacional, v. 20, 1984. p. 15-24: Regis Duprat. Antecipando a história da música no Brasil. Idem, p. 25-28.

17. Regis Duprat \& Jaelson Trindade. Uma descoberta musicológica: os manuscritos musicais de Mogi das Cruzes, c. 1730. In: II ENCONTRO NACIONAL DE PESQUISA EM MÚSICA. Belo Horizonte. Imprensa da UFMG, 1986. p. 52-53) trazem estas informações sobre os "Bradados a 4" e os "Tractos" de Faustino do Prado Xavier: "Assim. arrolamos sete manuscritos oriundos de várias cidades do Vale do Paraíba e da Serra do Mar, e um exemplar de Porto Feliz, a oeste de Săo Paulo. As cidades do Vale são: Aparecida ( 2 manuscritos) e Guaratinguetá: e os da Serra do Mar: Cunha (2 manuscritos) e São Luís do Paraitinga, (2). Um destes últimos parece tratar-se do mais antigo dentre os demais (apenas uma parte do contralto), porém. não datado, traz a escritura original reforçada por decalque mais recente, dificultando conclusóes mais definidas.

Dentre os manuscritos datados, um dos de Aparecida é o mais antigo. De 1863, é proveniente da cidade mineira de Itajubá, serra acima, ali copiado por Francisco José de Lorena que. nessa 
década, se radica no Vale, onde constitui uma linhagem de músicos de Aparecida do Norte. Seria ele o portador do novo protótipo das obras compostas no mesmo Valc. cerca de 1.30 anos antes e, a partir de entâo ali refundidas como difundidas foram nas Gerais em período anterior: e alí permaneceram, executadas e recopiadas. Não é outra a razão de encontrarmos dois ítens dessas obras no catálogo de microfilmes do Ciclo do Ouro. Uma. no Museu da Música. de Mariana (p. 269): "Pa. sexta fra."; outra, na Lira Sanjoanense, de São João del-Rei (p. 271). em cópia de 1928 e autoria atribuída, no catálogo, a Manoel Dias de Oliveira".

18. Elmer Correa Barbosa, org. O Ciclo do Ouro. Rio de Janeiro: PUC e XEROX. 1978. 454 p.

19. Regis Duprat, Garimpo Musical. São Paulo: Novas Metas. 1985. p.18. 